\title{
The bond between country and brand stereotypes: insights on the role of brand typicality and utilitarian/hedonic nature in enhancing stereotype content transfer
}

Bond between country and brand stereotypes

\author{
Adamantios Diamantopoulos and Ilona Szőcs \\ Marketing and International Business, University of Vienna, Vienna, Austria \\ Arnd Florack \\ Applied Social Psychology and Consumer Research, University of Vienna, \\ Vienna, Austria \\ Živa Kolbl \\ Marketing, School of Economics and Business, University of Ljubljana, \\ Ljubljana, Slovenia, and \\ Martin Egger \\ Applied Social Psychology and Consumer Research, University of Vienna, \\ Vienna, Austria
}

\begin{abstract}
Purpose - Drawing on the stereotype content model (SCM), the authors investigate the stereotype content transfer (in terms of warmth and competence) from country to brand and the simultaneous impact of these two stereotypes on consumer responses toward brands.

Design/methodology/approach - The authors test a structural equation model conceptualizing brand stereotypes as full mediators between country stereotypes and consumer outcomes. In addition, in a moderated mediation analysis, the authors investigate the role of brand typicality and utilitarianism/hedonism in potentially moderating the country to brand stereotype content transfer.

Findings - Country warmth and competence, respectively, impact brand warmth and competence, thus confirming the hypothesized stereotype content transfer. This transfer is found to be robust and not contingent on brands' perceived typicality of their country of origin. However, brands' utilitarian nature amplifies the positive impact of country competence on brand competence. Finally, brand stereotypes fully mediate the impact of country stereotypes on consumers' brand attitudes and behavioral intentions.

Originality/value - The authors provide the first empirical attempt that (1) explicitly differentiates between consumers' stereotypical perceptions of countries and stereotypical perceptions of brands from these countries, (2) empirically examines the transfer of stereotypical dimensions of different targets (i.e. country to brand),
\end{abstract}

(C) Adamantios Diamantopoulos, Ilona Szőcs, Arnd Florack, Živa Kolbl and Martin Egger. Published by Emerald Publishing Limited. This article is published under the Creative Commons Attribution (CC BY 4.0) licence. Anyone may reproduce, distribute, translate and create derivative works of this article (for both commercial and non-commercial purposes), subject to full attribution to the original publication and authors. The full terms of this licence may be seen at http://creativecommons.org/licences/by/4.0/ legalcode

The authors thank Associate Editor Professor Mark Cleveland and four anonymous reviewers for their helpful comments on earlier drafts of the manuscript.

This study has been conducted as part of the Austrian Science Fund (FWF) funded project "Navigating Brand Preference through Consumers' Stereotypes" (Project Nr. I 3727-G27).

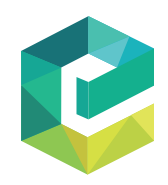

International Marketing Review Emerald Publishing Limited $0265-1335$ DOI 10.1108/IMR-09-2020-0209 
(3) explores boundary conditions for such transfer and (4) simultaneously considers the impact of both kinds of stereotypes on managerially relevant consumer outcomes.

Keywords Country stereotypes, Brand stereotypes, Stereotype content transfer

Paper type Research paper

\section{Introduction}

In recent years, the concept of stereotyping has been increasingly applied in international marketing research, particularly in country of origin (COO) studies (e.g. Chen et al., 2014; Diamantopoulos et al., 2017; Magnusson et al., 2019). Stereotypes capture the cognitive dimension of social perception and are defined as a "socially shared set of beliefs about traits that are characteristic of members of a social category" (Greenwald and Banaji, 1995, p. 14). For example, the stereotype of people living in a country as competent and hardworking may lead to an expectation that products and brands stemming from that country will be of good quality. However, this belief alone does not automatically mean that consumers will seek to purchase the country's products/brands because it fails to account for the perceived idiosyncratic characteristics of the brand itself. Such characteristics are reflected in brand stereotypes, which capture "consumers' beliefs about brands as intentional agents (Kervyn et al., 2012) and such beliefs can guide consumer perceptions (e.g. brand evaluations), intentions (e.g. purchase intentions) and actual behavior (e.g. brand ownership)" (Kolbl et al., 2019, p. 614). Surprisingly, in an international marketing context, the relevant literature has been focusing - almost exclusively - on country stereotypes, whereas the role of brand stereotypes and their relation to country stereotypes have rarely been examined.

The brand and its COO may be regarded as extrinsic cues in a multi-cue consumer decision-making context (e.g. Miyazaki et al., 2005; Teas and Agarwal, 2000). Such cues form the basis for consumer information processing and can activate stereotypical perceptions related to the brand's intentions and abilities (e.g. Aaker et al., 2012) as well as stereotypical perceptions of the brand origin (e.g. Halkias and Diamantopoulos, 2020). The related literature further shows that consumers' allocation of brands into global/local mental categories transfers to every product for which category membership is established and, consequently, shapes brand responses (Davvetas and Halkias, 2019). This implies that brand stereotypes can be charged with the stereotypical content of a superordinate category (such as their (OO). For example, Mercedes may be seen as an able brand because it carries stereotypes about German competence. Such transfer of stereotypical beliefs is consistent with the process of irradiation through which consumers transfer their beliefs of brands' origin to brands (e.g. Diamantopoulos et al., 2011). While the interplay between brand origin and brand stereotypes is very likely, and several studies have shown that brand stereotypes can influence attitudinal and behavioral consumer responses (e.g. Aaker et al., 2012; Ivens et al., 2015), extant research has not yet explicitly investigated the relationship between brand origin and brand stereotypes.

Consumers' perceptions of countries and related brands are rarely free from any product associations, and COO scholars argue that such perceptions are product-specific (Jaffe and Nebenzahl, 2006). Some brands may be more strongly associated with a particular country (i.e. perceived as typical, such as Armani and Italy) than others. Typicality is often seen by consumers as yet another extrinsic cue from which inferences about brand quality and brand status are made (Spielmann, 2016; Tseng and Balabanis, 2011). In addition to typicality, the utilitarian and hedonic nature of brands has been linked to the stereotypical dimensions of warmth and competence (e.g. Chattalas, 2015; Chattalas and Takada, 2013).

In an attempt to understand the link between country and brand stereotypes, our study seeks to answer the following three key questions: (1) To what extent are brand stereotypes influenced by the country stereotypes associated with the brand origin? (2) Is the relation 
between country and brand stereotypes dependent on brand characteristics such as brands' typicality or their utilitarian/hedonic nature? (3) How do country and brand stereotypes act in concert to influence consumer attitudes and behavioral intentions? To our best knowledge, no research to date has investigated the transfer of stereotypical content between country and brand stereotypes, and the simultaneous role of both stereotypes as predictors of consumer responses.

Against this background, the objectives of the present study are to (1) examine the content
transfer between country and brand stereotypes, (2) investigate the role of brand typicality
and utilitarianism/hedonism in potentially moderating this transfer and (3) simultaneously
assess the impact of both kinds of stereotypes on attitudinal and behavioral responses.
Specifically, we propose that consumers form stereotypical beliefs about brands partly
through their stereotypical country-level beliefs. That is, judgments of country stereotypes
transfer to individual brands stemming from the respective countries and determine
consumer responses. We further propose that this stereotype transfer is facilitated by brand
typicality and that it is dependent on the nature of the focal brands (i.e. utilitarian vs. hedonic).

Against this background, the objectives of the present study are to (1) examine the content
transfer between country and brand stereotypes, (2) investigate the role of brand typicality
and utilitarianism/hedonism in potentially moderating this transfer and (3) simultaneously
assess the impact of both kinds of stereotypes on attitudinal and behavioral responses.
Specifically, we propose that consumers form stereotypical beliefs about brands partly
through their stereotypical country-level beliefs. That is, judgments of country stereotypes
transfer to individual brands stemming from the respective countries and determine
consumer responses. We further propose that this stereotype transfer is facilitated by brand
typicality and that it is dependent on the nature of the focal brands (i.e. utilitarian vs. hedonic).

Against this background, the objectives of the present study are to (1) examine the content
transfer between country and brand stereotypes, (2) investigate the role of brand typicality
and utilitarianism/hedonism in potentially moderating this transfer and (3) simultaneously
assess the impact of both kinds of stereotypes on attitudinal and behavioral responses.
Specifically, we propose that consumers form stereotypical beliefs about brands partly
through their stereotypical country-level beliefs. That is, judgments of country stereotypes
transfer to individual brands stemming from the respective countries and determine
consumer responses. We further propose that this stereotype transfer is facilitated by brand
typicality and that it is dependent on the nature of the focal brands (i.e. utilitarian vs. hedonic).

Against this background, the objectives of the present study are to (1) examine the content
transfer between country and brand stereotypes, (2) investigate the role of brand typicality
and utilitarianism/hedonism in potentially moderating this transfer and (3) simultaneously
assess the impact of both kinds of stereotypes on attitudinal and behavioral responses.
Specifically, we propose that consumers form stereotypical beliefs about brands partly
through their stereotypical country-level beliefs. That is, judgments of country stereotypes
transfer to individual brands stemming from the respective countries and determine
consumer responses. We further propose that this stereotype transfer is facilitated by brand
typicality and that it is dependent on the nature of the focal brands (i.e. utilitarian vs. hedonic).

Against this background, the objectives of the present study are to (1) examine the content
transfer between country and brand stereotypes, (2) investigate the role of brand typicality
and utilitarianism/hedonism in potentially moderating this transfer and (3) simultaneously
assess the impact of both kinds of stereotypes on attitudinal and behavioral responses.
Specifically, we propose that consumers form stereotypical beliefs about brands partly
through their stereotypical country-level beliefs. That is, judgments of country stereotypes
transfer to individual brands stemming from the respective countries and determine
consumer responses. We further propose that this stereotype transfer is facilitated by brand
typicality and that it is dependent on the nature of the focal brands (i.e. utilitarian vs. hedonic).

Against this background, the objectives of the present study are to (1) examine the content
transfer between country and brand stereotypes, (2) investigate the role of brand typicality
and utilitarianism/hedonism in potentially moderating this transfer and (3) simultaneously
assess the impact of both kinds of stereotypes on attitudinal and behavioral responses.
Specifically, we propose that consumers form stereotypical beliefs about brands partly
through their stereotypical country-level beliefs. That is, judgments of country stereotypes
transfer to individual brands stemming from the respective countries and determine
consumer responses. We further propose that this stereotype transfer is facilitated by brand
typicality and that it is dependent on the nature of the focal brands (i.e. utilitarian vs. hedonic).

Against this background, the objectives of the present study are to (1) examine the content
transfer between country and brand stereotypes, (2) investigate the role of brand typicality
and utilitarianism/hedonism in potentially moderating this transfer and (3) simultaneously
assess the impact of both kinds of stereotypes on attitudinal and behavioral responses.
Specifically, we propose that consumers form stereotypical beliefs about brands partly
through their stereotypical country-level beliefs. That is, judgments of country stereotypes
transfer to individual brands stemming from the respective countries and determine
consumer responses. We further propose that this stereotype transfer is facilitated by brand
typicality and that it is dependent on the nature of the focal brands (i.e. utilitarian vs. hedonic).

Against this background, the objectives of the present study are to (1) examine the content
transfer between country and brand stereotypes, (2) investigate the role of brand typicality
and utilitarianism/hedonism in potentially moderating this transfer and (3) simultaneously
assess the impact of both kinds of stereotypes on attitudinal and behavioral responses.
Specifically, we propose that consumers form stereotypical beliefs about brands partly
through their stereotypical country-level beliefs. That is, judgments of country stereotypes
transfer to individual brands stemming from the respective countries and determine
consumer responses. We further propose that this stereotype transfer is facilitated by brand
typicality and that it is dependent on the nature of the focal brands (i.e. utilitarian vs. hedonic).

Against this background, the objectives of the present study are to (1) examine the content
transfer between country and brand stereotypes, (2) investigate the role of brand typicality
and utilitarianism/hedonism in potentially moderating this transfer and (3) simultaneously
assess the impact of both kinds of stereotypes on attitudinal and behavioral responses.
Specifically, we propose that consumers form stereotypical beliefs about brands partly
through their stereotypical country-level beliefs. That is, judgments of country stereotypes
transfer to individual brands stemming from the respective countries and determine
consumer responses. We further propose that this stereotype transfer is facilitated by brand
typicality and that it is dependent on the nature of the focal brands (i.e. utilitarian vs. hedonic).

\section{Conceptual background}

\subsection{Stereotyping and the stereotype content model (SCM)}

To theoretically anchor our study, we employ Fiske et al.'s (2002) stereotype content model (SCM), which is the most prominent model for capturing stereotype content and linking it to behavioral tendencies (Fiske, 2018). There is consensus in the literature that stereotypes represent oversimplified and generalized set of beliefs about the characteristics of a social group and are often referred to as "energy-saving devices that serve the important cognitive function of simplifying information processing and response generation" (Macrae et al., 1994, p. 37). Such cognitive stereotypical perceptions of others are captured by the SCM.

The SCM is an established theoretical framework that describes stereotypical perceptions of people according to two fundamental dimensions - warmth and competence. Warmth encompasses people's cognitive appraisals of whether others hold the intention to benefit or harm them. Intentions are seen as positive (i.e. warm) to the extent that they are cooperative, benevolent and free of conflict, and negative (i.e. cold) to the extent that they are competitive, malevolent and conflictual. Warmth captures positive notions such as good-natured, kind and friendly, while negative perceptions along the warmth dimension elicit notions in the opposite direction (such as hostile, cold and unfriendly). Competence refers to appraisals of how effectively others will pursue their (good or bad) intentions and encompasses people's cognitive appraisals about the ability of others to benefit or harm them. Competence is seen as positive to the extent that it implies high status and respect, and negative to the extent that it implies low status and disrespect. The SCM thus suggests that the content of stereotypes does not mirror a simple evaluative or affective response but instead reveals cognitive judgments on separate dimensions of (dis)like and (dis)respect. Stereotype content is often mixed, whereby subjectively positive stereotypes on one dimension (e.g. high warmth) are functionally consistent with unfavorable stereotypes on the other dimension (e.g. low competence).

The stereotype content dimensions by Fiske $e t$ al. (2002) have been successfully applied in prior research to differentiate the content of stereotypes for social groups (e.g. Lee and Fiske, 2006), countries (e.g. Diamantopoulos et al., 2017), organizations (e.g. Aaker et al., 2010) and brands (e.g. Kervyn et al., 2012). These studies have demonstrated that warmth and competence drive people's emotions and behavior toward the animate (people) as well as the inanimate world (countries, organizations, brands and products) and give credence to these stereotype dimensions as being fundamental and universal dimensions of social cognition.

The SCM has many advantages that render it particularly useful in empirical research. First, it narrows the content of stereotypes down to two basic dimensions, thus allowing for a
Bond between country and brand stereotypes

stereotypes

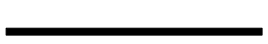


parsimonious representation of such content. Second, the selection of its core dimensions is not arbitrary but based on two fundamental aspects which dominate human impression formation and which are highly relevant for the perception of countries and brands as intentional agents (Kervyn et al., 2008). Third, the SCM allows systematic theory building by offering a validated framework for deriving concrete hypotheses about how consumers respond to countries and brands with different combinations of warmth and competence. Fourth, the SCM enables the operationalization of stereotypes at a higher level of abstraction that is not tied to product or category idiosyncrasies, thus promoting theory development and generalizability (Diamantopoulos et al., 2017).

\subsection{Country stereotypes}

Country stereotypes represent shared beliefs about traits, intentions and behaviors that are characteristic of people living in a country (Chattalas et al., 2008; Maheswaran, 1994; Samiee, 1994). These stereotypes are spontaneously activated upon exposure to COO cues and can impact brand assessments even in the absence of intention (Herz and Diamantopoulos, 2013). In international marketing, the idea of applying a stereotyping perspective has been voiced for a long time (e.g. Maheswaran, 1994), and several studies have used the SCM to capture country stereotypes (e.g. Chen et al., 2014; Diamantopoulos et al., 2017; Halkias et al., 2016).

COO stereotyping research suggests that consumers develop associations about people in countries and organize their judgments into mental schemas which influence brand evaluations (Magnusson et al., 2019). More specifically, country warmth reflects perceptions regarding the intentions, friendliness and cooperativeness of the inhabitants of a certain country, while country competence reflects corresponding perceptions regarding efficacy and efficiency.

A related yet conceptually distinct construct to country stereotypes in COO research is country image. Broadly described as "a mental network of affective and cognitive associations connected to the country" (Verlegh, 2001, p. 25), country image assessments elicit respondents' own beliefs and feelings toward a particular country. Thus, country image is a broader construct comprising a wide variety of conceptualizations (and measurement instruments) such as overall country image, product-country image and country-related product image (Roth and Diamantopoulos, 2009); macro- and micro-country image (Pappu et al., 2007) and basic-origin image, product-origin image and category-origin image (Josiassen et al., 2013).

The country stereotype and country image constructs can be differentiated in several aspects. First, despite the frequent but erroneous interpretation of the warmth dimension as representing affect (e.g. Chattalas et al., 2008; Dholakia et al., 2020), stereotypical country judgments capture cognitions only, which implies that "stereotypes and schemas do not fully capture the (country) image construct" (Roth and Diamantopoulos, 2009, p. 728). Second, country stereotypes do not even mirror the cognitive component of country image because the latter includes political, geographical, personal, socioeconomic and technological aspects (Brijs et al., 2011). Third, country stereotypes are conceptualized and operationalized at a higher level of abstraction than country images (which are often product-specific; Jaffe and Nebenzahl, 2006). Fourth, when measuring country stereotypes, respondents are always asked to state how people in a given society (e.g. Germans) perceive a target country's inhabitants in terms of warmth and competence. This third-person approach contrasts sharply with country image measurements which elicit respondents' own beliefs and feelings toward a particular country. Finally, at an operational level, the distinction between the country stereotype and country image constructs is aptly illustrated by the use of the former either as an antecedent of the latter or as a parallel predictor in empirical research models (Dholakia et al., 2020; Motsi and Park, 2019). 
Another widely used construct related to country stereotypes is country affinity, defined as "[a] feeling of liking, sympathy, and even attachment toward a specific foreign country" (Oberecker et al., 2008, p. 26). Country affinity relates to emotional associations or feelings consumers have about the target country and "is conceptualized purely as an affective attachment to a specific country" (Oberecker et al., 2008, p. 26). In contrast, country stereotypes capture shared cognitions (beliefs) and do not reflect emotions toward the target country (Fiske et al., 2002; Halkias and Diamantopoulos, 2020).

\subsection{Brand stereotypes}

While the international marketing literature has been studying the role of country stereotypes, a parallel research stream in the branding literature has been focusing on brand stereotypes. According to the seminal work of Kervyn et al. (2012) on the Brands as Intentional Agents Framework (BIAF), brand relationships are driven by the same two overarching dimensions that drive social perceptions (i.e. warmth and competence). As with human social interactions, consumers perceive the specific content of a brand's stereotype (i.e. $\mathrm{good} / \mathrm{bad}$ intentions and its ability/inability to enact those intentions), and this influences their attitudes and behavior toward the brand. Consumers, for example, can appreciate the potential of a brand to develop smart and reliable solutions for existing problems or regard the brand as competent to remain a market leader for a long time (attribution of high competence, e.g. Apple). Similarly, consumers can perceive a brand as acting only in selfinterest, neglecting the needs of the society and of the consumers (attribution of low warmth, e.g. Deutsche Bank).

It is important to distinguish brand stereotypes from related yet distinct constructs such as brand image and brand personality. The construct of brand image captures three types of consumers' associations with a brand: cognitive-, emotional- and sensory associations (Cho and Fiore, 2015). Thus, brand stereotypes encompass consumers' shared cognitions, while brand image holistically encompasses consumers' brand associations.

Another important difference between the constructs lies in their operationalization. Like country stereotypes, brand stereotypes are assessed by applying a third-person technique, in order to capture shared beliefs within a given society (as well as to overcome potential threats of social desirability bias). Specifically, when measuring brand stereotypes, respondents are asked to state how most people within a certain society perceive a particular brand (Kervyn et al., 2012). This is very different from the way in which brand image is typically measured, where respondents are asked to indicate their own (i.e. personal) associations with a particular brand.

The social perception of brands has common grounds in the notion of anthropomorphism, which refers to seeing the human in nonhuman forms (Guthrie, 1995). In a marketing context, anthropomorphism refers to assigning human-like characteristics and features to brands. Research shows that consumers are indeed able to assign personality qualities to inanimate objects, such as brands (Aaker, 1997). Fournier's work $(1998,2009)$ on the notion that people relate to brands quite similarly as they do to other people, provided a common foundation for the study of consumer-brand relationships and relevant constructs that have been transferred from social psychology to the marketing context (e.g. personality and stereotypes). Researchers studying brand stereotypes recognize that "there are clear links between our brand perception model and Aaker's (1997) brand personality scale" (Kervyn et al., 2012, p. 171). However, whereas brand personality references "the set of human characteristics associated with a brand” (Aaker, 1997, p. 347), brand stereotypes represent consumers' oversimplified and generalized beliefs about brands as intentional agents (Kervyn et al., 2012).

Brand personality and brand stereotypes also have a different target focus. As Kervyn et al. (2012, p. 171) explain, "personality scales make sense when focusing on one or on a small number of brands, to provide a more detailed description of their actual attributes. Social 
perception models on the other hand allow researchers to measure perception of a larger number of social objects, thus creating a whole landscape in which the images of all the relevant objects can be located and compared." Thus, brand personality deals with individual perception and represents the fit between self-versus brand perception, whereas the brand stereotype construct deals with social perception. This view is congruent with that in psychology, which speaks of a distinction between "personality scales (what a person is) and social perceptions (how a person appears)" (Kervyn et al., 2012, p. 171).

The stronger focus on shared beliefs in brand stereotypes compared to brand personality traits is also apparent in the measurement of the two constructs. When evaluating brand personality, respondents are asked about their individual perception of how well the items represent or describe a certain brand (e.g. Coca-Cola is: exciting) (Aaker, 1997). In contrast, when evaluating brand stereotypes, respondents are asked about a common consensus of a society (e.g. Most people in Germany think that Coca-Cola is: competent) (Fiske et al., 2002; Kervyn et al., 2012).

Next, while brand personality is associated with human characteristics of the brand, it does not conceptualize brands as intentional agents (i.e. their perceived intentions and ability), which is fundamental to the BIAF (Fournier and Alvarez, 2012). Furthermore, the two constructs differ in their end goal: brand personality pursues the goal of focusing on a smaller number of brands, resulting in a detailed description of a brand's attributes (Aaker, 1997), whereas brand stereotypes capture a much broader set of perceptions (Kervyn et al., 2012).

To summarize, both the construct of brand personality and the construct of brand stereotypes are essential to understanding people's social perceptions of brands, but have different, yet potentially reinforcing roles on consumer behavior. In this context, brand personality has been modeled as an antecedent of brand stereotypes (Ivens et al., 2015), meaning that the attributes of brands, which sum up into brand personality, are helpful in predicting the content of brand stereotypes as reflected in warmth and competence. Table 1 provides a summary of the conceptual definitions of country/brand stereotypes and related constructs.

\subsection{Stereotype content transfer}

A basic function of stereotypes is to provide individuals with the ability to make quick and simplified judgments (Bodenhausen, 1993). This function of stereotypes as "energy-saving

\section{Country stereotype \\ "Stored beliefs about characteristics of a specific country which are socially shared" (Herz and Diamantopoulos, 2013, p. 402)}

\section{Country image}

"A mental network of affective and cognitive associations connected to the country" (Verlegh, 2001, p. 25)

\section{Country affinity}

"A feeling of liking, sympathy, and even attachment toward a specific foreign country that has become an in-group as a result of the consumer's direct personal

Table 1.

Country/brand experience and/or normative exposure and that positively affects the consumer's decision-making stereotypes and related constructs associated with products and services originating
from the affinity country" (Oberecker et al., 2008, p. 26)

\begin{abstract}
Brand stereotype
"Brands are seen as intentional agents and thus [...] their perceived intentions and ability are important dimensions underlying brand perception” (Kervyn et al., 2012, p. 174)

\section{Brand image}

"The concept of a brand held by the consumer and is largely a subjective and perceptual phenomenon formed through consumer interpretation" (Dobni and Zinkhan, 1990, p. 118)

\section{Brand personality}

"The set of human characteristics associated with a brand" (Aaker, 1997, p. 347)
\end{abstract}


devices" (Macrae et al., 1994, p. 37) is supported by automatic processes that follow the categorization of an individual or object (Herz and Diamantopoulos, 2013). Such categorization leads to an automatic activation of stereotypic beliefs which are then expected to be applied to the members of the category. Hence, it is likely that consumers make inferences about a brand based on the country stereotype once they have categorized the brand as originating from a certain country. Because this process is repeated each time when consumers are exposed to a brand, we argue that the content of country stereotypes (in terms of warmth and competence) transfers, at least partly, to brand stereotypes and that such transfer can generally be expected irrespective of consumers' familiarity with the stimulus brand. The reason for the expected direction of the transfer is that the pairing of a brand with a certain COO is likely to lead to associative learning (Teichert and Schöntag, 2010), which results in an automatic association of the brand with the beliefs about the people living in the brand's $\mathrm{COO}$. We do not expect a strong transfer from the brand to the country because any given brand is paired with the same country during associative learning all the time, but a given country is paired with many different brands. Hence, because the stimulus brand is only one of a multitude of brands linked to a particular country, it is much less likely that the brand will have a similar influence on the country (in terms of stereotype content transfer) as the country has on the brand.

In light of the above, we expect that perceptions of a brand's $\mathrm{COO}$ as warm and having good intentions will prompt in consumers' minds that the brand is trustworthy, safe and harmless, while perceptions of being a generally competent country (e.g. technologically advanced) will instill more confidence in the quality of products from that country (Xu et al., 2013). We thus hypothesize that:

H1a. Judgments of country warmth positively predict judgments of brand warmth.

H1b. Judgments of country competence positively predict judgments of brand competence.

\subsection{The relevance of brand typicality and hedonic/utilitarian properties}

Stereotypical beliefs are not applied equally to all members of a category, and the likelihood of applying such beliefs to judge a category member decreases when this member is perceived as being less typical of the category (Oakes et al., 1991). Typicality is defined as the degree to which an item is perceived to represent a category (Loken and Ward, 1990). Typicality influences the activation and use of a category such that individuals adapt the use of stereotypes to targets that fit the representation of the category (Oakes and Turner, 1990).

In the context of brands, typicality reflects the degree of association between a brand and a country, whereby "the more typical a brand is of its BO [brand origin], the stronger are the associations between the brand and the BO" (Hamzaoui-Essoussi et al., 2011, p. 974). Previous research suggests that consumer evaluation of brands depends on more than just their COO and calls for considering both origin stereotypes and typicality when investigating consumers' brand evaluations (Spielmann, 2016). While some brands may be strongly associated with a particular country (such as Mercedes with Germany; Usunier and Cestre, 2007), other brands may not be associated with a country (e.g. Heineken with the Netherlands). Brands can thus be perceived as being more or less typical of their $\mathrm{COO}$ and such perceptions influence consumers' judgments about a brand (Tseng and Balabanis, 2011). Typicality is often seen by consumers as an identity cue from which inferences about brand quality and brand status are made and has been found to influence the impact of $\mathrm{COO}$ on key consumer outcomes, such as brand equity (Hamzaoui-Essoussi et al., 2011) and willingness to buy (Usunier and Cestre, 2007). Moreover, previous research supports that the strength of the association between the brand and its origin moderates the effect of COO on consumer evaluations of brands (Andéhn and Decosta, 2016). 
This indicates that the effect of $\mathrm{COO}$ can be weaker or stronger depending on the association strength linking the brand to an origin in the mind of the customer.

Following the above logic, we propose that the country stereotype effect is not identical for all brands, and that perceived brand typicality aids consumers in making associations between the brand and its origin. Specifically, the strength of the stereotype transfer may vary depending on the extent to which the brand's origin is perceived as the country which consumers typically associate with the brand; a brand seen as highly typical of its origin is likely to benefit more from positive brand-country associations, whereas a brand with lower perceived typicality will benefit less. Accordingly, the transfer of country stereotypes to brand stereotypes is expected to be stronger when a brand appears highly typical of its origin and weaker when the brand appears less typical of its origin. Therefore, we posit that the degree of typicality of a brand as a representative of its $\mathrm{COO}$ will positively moderate the transfer of country stereotypes to brand stereotypes.

H2a. The stereotype transfer effect between country warmth and brand warmth is positively moderated by brand typicality.

$H 2 b$. The stereotype transfer effect between country competence and brand competence is positively moderated by brand typicality.

In addition to typicality, other determinants of the meaningfulness of the country category for the judgment of a brand also affect the stereotype content transfer on the dimensions of warmth and competence. We expect that the perceived hedonic or utilitarian nature of brands could potentially be such a factor because it can render a transfer of the characteristics on these dimensions more or less meaningful for consumers. Hedonic properties relate to experiential benefits (e.g. fun) of brands, while utilitarian properties reflect functional benefits (e.g. premium quality) (Voss et al., 2003). Importantly, these two properties are usually not mutually exclusive (Batra and Ahtola, 1991) and have been discussed in relation to country stereotypes. Specifically, country warmth has been found to be related to greater expectations of hedonic properties, while country competence to greater expectations of utilitarian properties (Chattalas and Takada, 2013). We thus expect that the perception of a brand as hedonic should facilitate the transfer of warmth, whereas the perception of a brand as utilitarian should facilitate the transfer of competence. Consequently, brands with a warm (competent) country association are expected to transfer their stereotypical warmth (competence) on the brand stereotype warmth (competence) more strongly when these brands are perceived as more hedonic (utilitarian).

H3a. The stereotype transfer effect between country warmth and brand warmth is stronger for brands perceived to be predominantly hedonic.

$H 3 b$. The stereotype transfer effect between country competence and brand competence is stronger for brands perceived to be predominantly utilitarian.

\subsection{Stereotype impact: attitudinal and behavioral outcomes}

The usefulness of country and brand stereotypes as explanatory constructs in a consumer behavior context is, ultimately, dependent on their ability to predict brand attitude and purchase decisions. With regard to country stereotypes, extant research has linked country warmth and competence directly to brand evaluations, such as brand affect (e.g. Diamantopoulos et al., 2017), brand attitude (e.g. Halkias et al., 2016) and customer-based brand equity (e.g. Magnusson et al., 2019). Regarding brand stereotypes, brands' perceived intentions and ability (i.e. warmth and competence) positively and independently predict purchase intentions as well as brand loyalty (Kervyn et al., 2012). Well-intentioned brands (i.e. brands perceived as warm) are associated with higher purchase intent and brand loyalty than 
ill-intentioned brands. Similarly, high-ability brands (i.e. brands perceived as competent) are associated with higher purchase intent and brand loyalty than low-ability brands. More recent research on brand stereotypes has further highlighted the effects of warmth and competence stereotypes on consumer responses toward brands (Davvetas and Halkias, 2019; Kolbl et al., 2019, 2020).

While the above findings suggest that both country and brand stereotypes are relevant for consumers when evaluating brands, the simultaneous impact of country and brand stereotypes on managerially-relevant consumer outcomes has not yet been examined. However, the interdependence of these stereotypes appears to be theoretically warranted. Several studies indicate that consumers transfer their stereotypical perceptions between different stereotypical targets (e.g. Antonetti and Maklan, 2016; Diamantopoulos et al., 2011; Nebenzahl et al., 2003). Thus, it is highly unlikely that consumers' stereotypical judgments of countries and brands are developed in isolation of each other. For example, how likely is it that a consumer's stereotype of Germany would not affect her/his stereotypical image of Mercedes? Consequently, the sole focus on the previously identified direct effects of country stereotypes on consumer outcomes neglects potentially relevant indirect effects of these stereotypes via brand stereotypes. We thus propose that the impact of country warmth and competence will be channeled through the corresponding dimensions of brand stereotypes. Specifically, and consistent with our earlier argumentation on the expected stereotype content transfer (see H1a and H1b), in the structural equation model, we model brand stereotypes as full mediators on the linkage between country stereotypes and consumers' brand-related responses (see Figure 1).

H4a. Judgments of country warmth indirectly and positively impact brand attitude and purchase intentions through brand warmth.

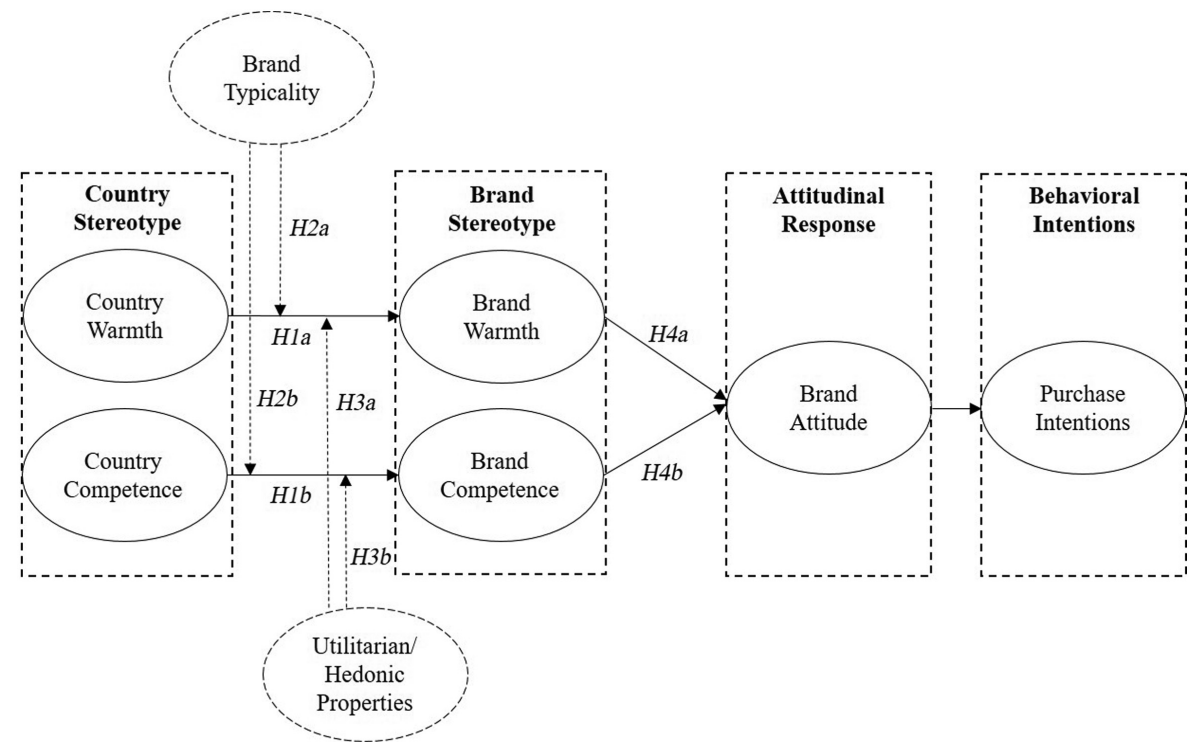

Note(s): While not shown, brand familiarity is used as a control variable on brand attitude and purchase intentions during estimation

Bond between country and brand stereotypes

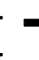


H4b. Judgments of country competence indirectly and positively impact brand attitude and purchase intentions through brand competence.

Consumer intentions to buy a brand may be affected by brand familiarity, namely "the extent of a consumer's direct and indirect experience with a brand" (Campbell and Keller, 2003, p. 293). Brand familiarity reduces the mental effort when making choices and facilitates habitual purchase behavior, and prior research has repeatedly emphasized its usefulness in models linking country or brand-related drivers to outcome variables (e.g. Diamantopoulos et al., 2011; Kolbl et al., 2019). Thus, in order to avoid model misspecification (i.e. biased parameter estimates and lower explained variance), we explicitly control for the effects of brand familiarity when testing our model shown in Figure 1.

\section{Methodology}

\subsection{Research design and construct measurement}

We test our hypotheses in an economically advanced European country (Austria), employing a nationally representative sample in terms of gender and age. Four hundred and eleven consumers $\left(50.40 \%\right.$ female, $\left.M_{\text {age }}=42.19, \mathrm{SD}_{\text {age }}=15.14\right)$ were recruited in August 2018 in a between-subjects, online survey conducted by a professional marketing research agency. Respondents were informed that the aim of the survey was to assess perceptions of products, brands and countries and were instructed to answer spontaneously. We provided anonymity and confidentiality assurances and emphasized that there were no right or wrong answers. Participants were randomly presented with one of eight well-known brands and the corresponding COO (i.e. Evian/France, Giorgio Armani/Italy, IKEA/Sweden, Sony/Japan, Heineken/the Netherlands, Apple/USA, Zara/Spain and Mercedes-Benz/Germany) and responded to questions relating to the country stereotypes, brand stereotypes, brand attitude, purchase intentions and brand familiarity. The order of questions relating to the different stereotypes was counterbalanced and randomized across respondents to control for potential order effects. We presented the brand and the corresponding country both verbally (i.e. written brand name and country name) and visually (i.e. brand logo and country flag). The rationale for selecting the eight brands was that these varied in terms of their $\mathrm{COO}$ and represented different product categories so as to ensure sufficient variation in terms of stereotype content. Based on previous research on country stereotypes (e.g. Diamantopoulos et al., 2017), we selected countries representing different country clusters, such as high warmth/low competence (e.g. Spain and Italy), low warmth/high competence (e.g. France, Sweden, Japan and Netherlands) and very low warmth/very high competence (e.g. Germany).

We applied Fiske $e$ t al.'s (2002) SCM dimensions of warmth and competence to measure the content of the country and brand stereotypes. Specifically, consistent with Diamantopoulos et al. (2017) when measuring country stereotypes, and Kolbl et al. (2019) when measuring brand stereotypes, we adopted four items per dimension scored on a five-point scale (warmth: friendly, good-natured, kind and warm; competence: capable, competent, efficient and intelligent). Respondents indicated their beliefs about how most people in the country of investigation (i.e. Austria) view the target brands and the corresponding origin countries, including their inhabitants, along these items. Furthermore, participants provided ratings on established multi-item scales for brand attitude (Keller and Aaker, 1992), purchase intentions (Dodds et al., 1991) and brand familiarity (Diamantopoulos et al., 2005).

To measure the moderators (i.e. brand typicality and brand utilitarianism/hedonism), we conducted a separate study. Specifically, 211 Austrian consumers were recruited in a betweensubjects online survey and exposed to the same eight stimulus brands as in the main study. The sample composition in terms of age and gender mirrored that of the main study $\left(M_{\text {age }}=40.52\right.$, $\mathrm{SD}_{\text {age }}=13.46,51.7 \%$ female). Brand typicality was measured with a three-item scale adapted 
from Hamzaoui-Essoussi et al. (2011) and Loken and Ward (1990); we computed the mean value for each brand and assigned this value to the respective brand in the main sample. Perceptions of brand utilitarianism and hedonism were measured with five-item scales drawn from Voss et al. (2003); we first computed the mean value for each dimension and then derived a "net" score by subtracting the mean hedonic value from the mean utilitarian value. Thus, positive scores on the resulting variable indicate that the brand is perceived to be more utilitarian than hedonic, whereas negative scores indicate the opposite. The measurement scales and psychometric properties of all variables are summarized in Table 2.

Following Podsakoff et al. (2003), we took several steps to reduce common method variance (CMV) in our data. On the procedural side, we promised respondent anonymity, reduced evaluation apprehension by emphasizing that there are no "right" or "wrong" answers, counterbalanced the question order of the country and brand stereotypes and used a variety of response formats. Moreover, as mentioned above, we used a separate study to measure the moderating variables. Given that both the moderators themselves and the interaction term act as predictors in the moderation analysis, separate measurement of the moderators helps to minimize method effects.

On the statistical side, we included a marker variable in the research questionnaire (Lindell and Whitney, 2001). Specifically, we used the item "How familiar are you with social networking sites like Facebook, LinkedIn, etc.?” (measured on a seven-point scale anchored at not at all familiar/very familiar) which, from a conceptual point of view, was unrelated to the constructs analyzed in our model. We performed a partial correlation analysis of the items measuring our constructs and assessed whether the significance of their zero-order correlations changed when the marker variable was partialled out. Partialling out the marker variable did not materially affect the observed relationships. Specifically, 372 zero-order correlations were significant before, and 371 correlations remained significant after controlling for the marker variable. Thus, CMV did not pose a material problem in our study.

\subsection{Analysis and results}

3.2.1 Descriptive analysis. The positions of the eight brands are used as stimuli, and their respective $\mathrm{COO}$ on the dimensions of the $\mathrm{SCM}$ are plotted in Figure 2. It can be seen that the chosen stimuli countries/brands vary substantially in terms of stereotype content, with several displaying ambivalent stereotypes (having a more positive evaluation on one dimension and a more negative on the other). It can also be seen that while certain countrybrand combinations occupy close positions in terms of stereotype content (e.g. Germany and Mercedes), others differ substantially either on one dimension (e.g. USA and Apple in terms of competence) or even on both (e.g. Netherlands and Heineken). This pattern indicates that country and brand stereotypes are indeed distinct and vindicates our decision to incorporate both of them in our conceptual model.

3.2.2 Measurement model. We investigated the dimensionality, reliability, and validity of our measures with a confirmatory factor analysis (CFA) using LISREL 8.8. Model fit was satisfactory $\left(\chi^{2}=1055.211, \mathrm{DF}=329\right.$; RMSEA $=0.07$; NNFI $=0.97$; CFI $\left.=0.98\right)$. Standardized item loadings across constructs ranged from 0.78 to 0.97 and composite reliabilities from 0.91 to 0.97 . Moreover, average variance extracted (AVE) ranged from 0.71 to 0.89 and all AVEs exceeded the corresponding squared inter-construct correlations (i.e. shared variances), thus establishing discriminant validity (Fornell and Larcker, 1981; Table 3).

3.2.3 Structural equation model. To test hypotheses H1a, H1b, H4a and H4b, we estimated a structural equation model in line with Figure 1 and obtained acceptable overall fit $\left(\chi^{2}=1231.168, \mathrm{DF}=339 ; \mathrm{RMSEA}=0.08 ; \mathrm{NNFI}=0.97 ; \mathrm{CFI}=0.97\right)$. The relevant parameter estimates are shown in Table 4.
Bond between country and brand stereotypes 


\section{IMR}

\section{Country stereotype: Warmth $^{*}$}

(Fiske et al., 2002; Diamantopoulos et al., 2017)

The attribute friendly describes [target country and its inhabitants]

The attribute good-natured describes [target country and its inhabitants]

The attribute kind describes [target country and its inhabitants]

The attribute warm describes [target country and its inhabitants]

Country stereotype: Competence ${ }^{*}$

(Fiske et al., 2002; Diamantopoulos et al., 2017)

The attribute capable describes [target country and its inhabitants]

The attribute competent describes [target country and its inhabitants]

The attribute efficient describes [target country and its inhabitants]

The attribute intelligent describes [target country and its inhabitants]

Brand stereotype: Warmth $^{*}$

(Fiske et al., 2002; Kolbl et al., 2019)

The attribute friendly describes [target brand]

The attribute good-natured describes [target brand]

The attribute kind describes [target brand]

The attribute warm describes [target brand]

\section{Brand stereotype: Competence*}

(Fiske et al., 2002; Kolbl et al., 2019)

The attribute capable describes [target brand]

The attribute competent describes [target brand]

The attribute efficient describes [target brand]

The attribute intelligent describes [target brand]

\section{Brand attitude}

Keller and Aaker (1992)

The brand is low quality/high quality

The brand is inferior/superior

The brand is bad/good

The brand is worse than most brands/better than most brands

The brand is negative/positive

Purchase intention

Dodds et al. (1991)

It is very likely that I will buy this brand

I Will definitely try this brand

The probability that I will purchase this brand is very high

I Am willing to buy this brand

Brand familiarity

Diamantopoulos et al. (2005)

I Am not at all/very familiar with this brand

I Believe I am not at all/very informed about this brand

I Consider myself to be inexperienced/experienced with regard to this brand

\section{Brand typicality}

(Hamzaoui-Essoussi et al., 2011; Loken and Ward, 1990)

[Target brand] is unrepresentative/representative of [target country]

[Target brand] is atypical/typical of [target country]

[Target brand] is poor example/good example of [target country]

\section{Brand utilitarianism}

Voss et al. (2003)

[Target brand] is ineffectiveleffective

[Target brand] is unhelpful/helpful

[Target brand] is not functional/functional

Table 2.

Construct measures

[Target brand] is unnecessary/necessary

[Target brand] is impractical/practical

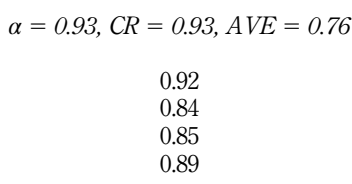

0.92

0.84

0.85

0.89

$\alpha=0.91, C R=0.91, A V E=0.72$

0.89

0.85

0.87

0.78

$\alpha=0.93, C R=0.93, A V E=0.78$

0.91

0.89

0.83

0.91

$\alpha=0.93, C R=0.93, A V E=0.77$

0.94

0.88

0.89

0.80

$\alpha=0.92, C R=0.92, A V E=0.71$

0.78

0.87

0.93

0.81

0.82

$\alpha=0.97, C R=0.97, A V E=0.89$

0.96

0.93

0.97

0.92

$\alpha=0.96, C R=0.95, A V E=0.86$

0.96

0.86

0.96

$\alpha=0.86, C R=0.87, A V E=0.69$

0.81

0.88

0.80

$\alpha=0.87, C R=0.87, A V E=0.58$

0.77

0.86

0.73

0.64

0.79 
Note(s): Country stereotype and brand stereotype items were measured on five-point scales and all other items on seven-point scales. Column entries are standardized factor loadings $\alpha=$ Cronbach's alpha, $C R=$ construct reliability, $A V E=$ average variance extracted

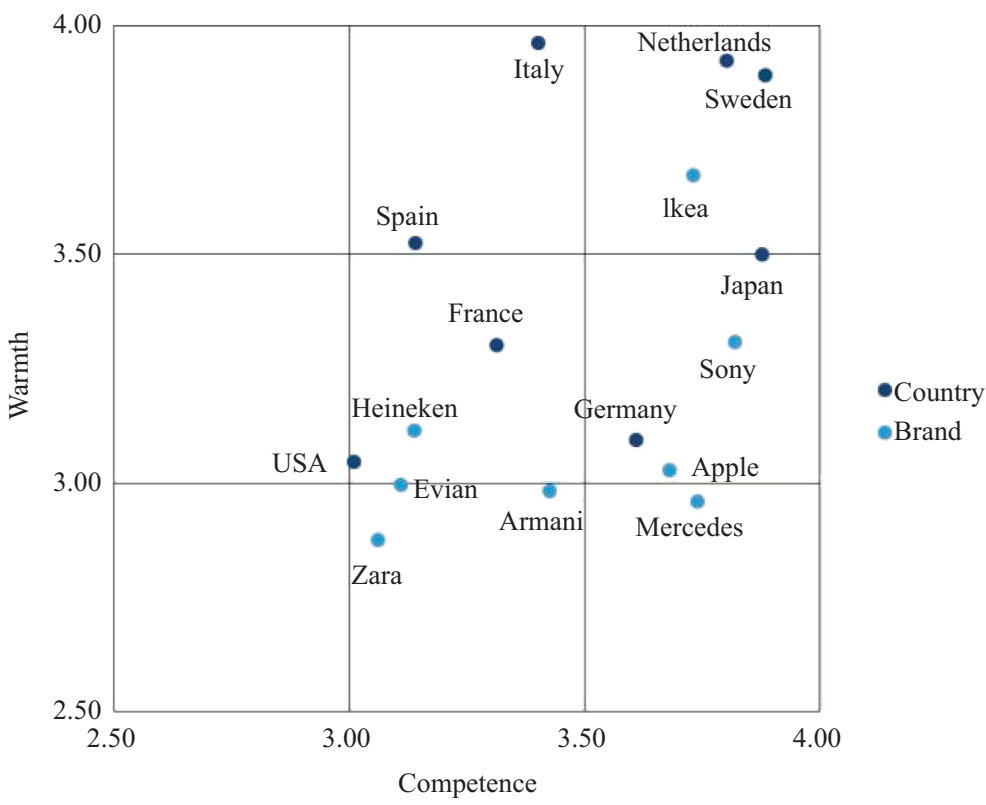

Note(s): Warmth and competence were measured on five-point scales $(1=$ totally disagree $/ 5=$ totally agree $)$
Figure 2.

Country and brand stereotype content (mean values)

\begin{tabular}{|c|c|c|c|c|c|c|c|c|c|}
\hline Construct & Mean & SD & 1 & 2 & 3 & 4 & 5 & 6 & 7 \\
\hline 1 Warmth $_{\text {country }}$ & 3.53 & 0.85 & 0.76 & & & & & & \\
\hline 2 Competence country & 3.50 & 0.81 & 0.36 & 0.72 & & & & & \\
\hline 3 Warmth $_{\text {brand }}$ & 3.11 & 0.95 & 0.14 & 0.25 & 0.78 & & & & \\
\hline 4 Competence $_{\text {brand }}$ & 3.46 & 0.91 & 0.05 & 0.18 & 0.45 & 0.77 & & & \\
\hline 5 Brand attitude & 5.00 & 1.24 & 0.04 & 0.11 & 0.22 & 0.33 & 0.71 & & \\
\hline 6 Purchase intention & 3.74 & 1.84 & 0.06 & 0.13 & 0.35 & 0.32 & 0.23 & 0.89 & \\
\hline 7 Brand familiarity & 3.44 & 1.75 & 0.02 & 0.09 & 0.20 & 0.22 & 0.10 & 0.52 & 0.86 \\
\hline
\end{tabular}

Note(s): Italics numbers on the diagonal show AVEs. Numbers on the off-diagonal represent the squared correlations between the constructs

Table 3.

Discriminant validity assessment 


\section{IMR}

\begin{tabular}{|c|c|c|c|}
\hline Path & Parameter estimate & Hypothesis & Supported \\
\hline \multicolumn{4}{|l|}{ Direct effects } \\
\hline Warmth $_{\text {country }} \rightarrow$ Warmth $_{\text {brand }}$ & $0.36^{* * * *}$ & H1a & YES \\
\hline Competence $_{\text {country }} \rightarrow$ Competence $_{\text {brand }}$ & $0.29 * * *$ & H1b & YES \\
\hline Warmth $_{\text {brand }} \rightarrow$ Brand attitude & $0.16^{* *}$ & & \\
\hline Competence $_{\text {brand }} \rightarrow$ Brand attitude & $0.45 * * *$ & & \\
\hline Brand attitude $\rightarrow$ Purchase intention & $0.30 * * *$ & & \\
\hline \multicolumn{4}{|l|}{ Indirect effects } \\
\hline Warmth $_{\text {country }} \rightarrow$ Brand attitude & $0.06^{*}$ & H4a & YES \\
\hline Warmth $_{\text {country }} \rightarrow$ Purchase intention & $0.02 *$ & H4a & YES \\
\hline Competence $e_{\text {country }} \rightarrow$ Brand attitude & $0.13^{* * * *}$ & $\mathrm{H} 4 \mathrm{~b}$ & YES \\
\hline Competence country $\rightarrow$ Purchase intention & $0.04 * * *$ & $\mathrm{H} 4 \mathrm{~b}$ & YES \\
\hline \multicolumn{4}{|l|}{ Control relationships } \\
\hline Brand familiarity $\rightarrow$ Brand attitude & 0.05 & & \\
\hline Brand familiarity $\rightarrow$ Purchase intention & 0.65 *** & & \\
\hline \multicolumn{4}{|c|}{ Note(s): Values represent standardized coefficients } \\
\hline
\end{tabular}

Country warmth had a significant positive effect on brand warmth $(\beta=0.36, p<0.001)$, supporting H1a. Country competence had a significant positive effect on brand competence $(\beta=0.29, p<0.001)$, supporting H1b. Moreover, both brand warmth $(\beta=0.16, p<0.01)$ and brand competence $(\beta=0.45, p<0.001)$ were positively related to brand attitude, and the latter had a positive effect on purchase intentions $(\beta=0.30, p<0.001)$. The indirect effects of country warmth via brand warmth on brand attitude $\left(\beta_{\text {INDIRECT }}=0.057, p<0.05\right)$ and purchase intentions $\left(\beta_{\text {INDIRECT }}=0.017, p<0.05\right)$ were both positive and significant thus supporting H4a. The corresponding indirect effects of country competence via brand competence on brand attitude $\left(\beta_{\text {INDIRECT }}=0.130, p<0.001\right)$ and purchase intentions $\left(\beta_{\text {INDIRECT }}=0.038, p<0.001\right.$ ) were also positive and significant, thus supporting H4b. Adding direct paths from country warmth and country competence to brand attitude did not improve model fit $\left(\Delta \chi^{2}=0.939, \Delta \mathrm{df}=2\right.$, n.s.), and all paths turned out to be nonsignificant (country warmth $\rightarrow$ brand attitude: $\beta=0.02$, n.s.; country competence $\rightarrow$ brand attitude: $\beta=0.06$, n.s.). These results demonstrate that brand stereotypes function as full mediators on the relationship between country stereotypes and consumer outcomes.

To investigate the relative strength of the stereotype content transfer in terms of warmth and competence, we compared our original model specification to a model incorporating equality constraints on the paths from country warmth to brand warmth and from country competence to brand competence. A chi-square difference test failed to produce a significant result $\left(\Delta \chi^{2}=1.157, \Delta \mathrm{df}=1\right.$, n.s.), indicating that the alternative model does not provide a worse fit to the data. Therefore, we conclude that the effects of the two country stereotype dimensions on the respective brand stereotype dimensions are of a similar magnitude.

As far as the relative strength of the links between the two brand stereotype dimensions and brand attitude is concerned, we compared our original model specification to a model incorporating equality constraints on the paths from brand warmth and brand competence to brand attitude. This time, the chi-square difference test produced a significant result $\left(\Delta \chi^{2}=10.126, \Delta \mathrm{df}=1, p<0.01\right)$, indicating that the alternative model provides a worse fit to the data. Therefore, we conclude that, compared to the effects of brand warmth, the effects of brand competence on brand attitude are stronger. Regarding the control relationship, brand 
familiarity positively and significantly impacted purchase intentions $(\beta=0.65, p<0.001)$ but not brand attitude $(\beta=0.05$, n.s.).

Country warmth explained $13 \%$ of the variance in brand warmth, while country competence explained $8 \%$ of the variance in brand competence. Overall, the model relations explained $32 \%$ of the variance in brand attitude and $55 \%$ of the variance in purchase intentions, indicating large effect sizes (Cohen, 1988).

3.2.4 Moderating effects. To test the potential conditioning effects of brand typicality (see $\mathrm{H} 2 \mathrm{a}$ and $\mathrm{H} 2 \mathrm{~b}$ ) and brand utilitarianism/hedonism (see H3a and $\mathrm{H} 3 \mathrm{~b}$ ), we conducted two separate moderated mediation analyses using PROCESS (model 7) with 5.000 bootstraps (Hayes, 2018), one with the warmth stereotypes and another with the competence stereotypes as predictors of brand attitude.

First, we investigated the moderating role of brand typicality. For the warmth dimension, a more positive origin stereotype was related to a more positive brand stereotype $(\beta=0.40$, $t=7.903, p<0.001)$. Brand typicality did not moderate this relationship $(\beta=0.15, t=1.668$, n.s.); however, it had a direct impact on brand warmth $(\beta=0.16, t=1.972, p<0.05)$. These results do not support H2a. Brand warmth was further positively linked to brand attitude $(\beta=0.59$, $t=9.572, p<0.001$ ), while the link from brand origin warmth to brand attitude was not significant $(\beta=0.04, t=0.651$, n.s.). For the competence dimension, a more positive origin stereotype was related to a more positive brand stereotype $(\beta=0.45, t=9.246, p<0.001)$. Again, brand typicality did not moderate this relationship $(\beta=0.08, t=0.827$, n.s.) but had a direct impact on brand competence $(\beta=0.46, t=6.347, p<0.001)$. These results do not support H2b. Brand competence was further positively linked to brand attitude $(\beta=0.70, t=11.399$, $p<0.001)$ and the link from brand origin competence to brand attitude was also significant $(\beta=0.17, t=2.431, p<0.05)$. Thus, contrary to expectations, brand typicality does not act as a moderator of stereotype content transfer but as an (additional) predictor of brand warmth and competence.

Next, we repeated the PROCESS analysis but used utilitarianism/hedonism as the moderating variable. For the warmth dimension, a more positive country stereotype was related to a more positive brand stereotype $(\beta=0.40, t=8.107, p<0.001)$. Consumers' perceptions of utilitarianism/hedonism did not moderate this relationship $(\beta=0.15, t=1.304$, n.s.); however, brands perceived as more utilitarian than hedonic had a direct positive impact on brand warmth $(\beta=0.29, t=2.877, p<0.01)$. These results do not support H3a. For the competence dimension, a more positive country stereotype was related to a more positive brand stereotype $(\beta=0.45, t=8.735, p<0.001)$, and consumer perceptions of brands' utilitarian/hedonic nature did positively moderate this relationship $(\beta=0.26, t=2.050$, $p<0.05)$. Specifically, brands perceived to be more utilitarian than hedonic display a stronger link between brand origin competence and brand competence. Further, brand utilitarianism/ hedonism had no direct impact on brand competence $(\beta=0.03, t=0.327$, n.s.). These results support H3b.

\section{Discussion and conclusions}

\subsection{Theoretical implications}

In this paper, we sought to enhance our theoretical understanding on the role of stereotyping in an international consumer behavior context by addressing an important, yet neglected issue in the extant literature: the stereotype content transfer. By explicitly differentiating between consumers' stereotypical perceptions of countries and stereotypical perceptions of brands from these countries, our study is - to the best of our knowledge - the first to empirically investigate the content transfer across different kinds of stereotypes. Our findings show that linking country and brand stereotypes in a sequential fashion and subsequently to consumers' attitudinal and behavioral outcomes provides a good fit to empirical data.
Bond between country and brand stereotypes

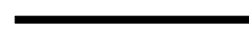


Drawing on the SCM for conceptual guidance, our results suggest that country and brand stereotypes are interlinked drivers of brand responses, where judgments of brand stereotypes already encapsulate judgments of country stereotypes. This is an important finding as it implies that the strength of the brand stereotype is partly attributable to the brand's COO stereotype. An interesting issue in this context is the perceived congruence between country and brand stereotypes. The observed positive impact on brand attitude and purchase intentions is consistent with recent research showing that brands are evaluated more favorably when the brand is positioned in a manner that is congruent with the brand's home country stereotype (Magnusson et al., 2019). Accordingly, the transfer of a favorable country stereotype to the brand stereotype may indicate a perceived consistency between the brand and its COO, resulting in a positive effect on brand attitude. However, while we find consistency in the content of the two stereotypes, we also find support for the distinctness of these stereotypes since origin-related beliefs do not fully transfer to positive brand-related beliefs. Country and brand stereotypes are clearly distinct as only a modest amount of variance in the brand stereotype dimensions is explained by the corresponding country stereotype dimensions. This implies that, while the country stereotype does matter, the brand stereotype incorporates additional consumer beliefs that are unique to the specific brand and cannot be traced back to judgments regarding the brand origin. Such consumer beliefs include perceptions of brands' personality (Ivens et al., 2015), beliefs about brands' globalness/localness (e.g. Davvetas and Halkias, 2019), the style of brand interaction (Wu et al., 2017), brands' green positioning strategies (Gong et al., 2020) and even perceptions of organizations' Internet domain name (.com vs. .org; Aaker et al., 2010). Thus, the assumption that the content of brand stereotypes is a simple reflection of the underlying country stereotypes - even under conditions of high typicality (see below) - is not warranted.

Our study also offers novel insights into the relationships between stereotypical dimensions across different stereotype targets and reveals their importance as drivers of consumers' behavioral intentions. In line with our conceptual model, we show that the activated country and brand stereotypes are interlinked within the same dimensions and are of uniform (positive) valence (i.e. high country warmth (competence) enhances brand warmth (competence)). Consistent with calls to account for typicality when investigating countrybrand linkages (e.g. Spielmann, 2016), we also assessed whether brand typicality facilitates stereotype content transfer. Our findings indicate that the instrumentality of the brand origin stereotype in predicting the brand stereotype is robust and not conditioned by country-brand typicality. The latter acts as an independent/additional antecedent of the brand stereotype dimensions rather than a moderating variable of stereotype content transfer. Typicality thus matters; however, it is less helpful in explaining the strength of stereotype content transfer from country to brand stereotypes. One reason for this unexpected effect could be that brand typicality provides yet another distinct cue that drives the brand stereotype content irrespective of the perceived warmth/competence of the brand's COO.

Further, we find that for brands perceived as predominantly utilitarian, the stereotype content transfer between country competence and brand competence is amplified. Thus, brands perceived as having a "fit" between their origin (i.e. competent country) and their features (i.e. functional brand) enjoy a more a positive brand competence stereotype, and ultimately, a more positive brand attitude. This finding adds to previous research suggesting a connection between $\mathrm{COO}$ effects and products' hedonic/utilitarian nature (Chattalas and Takada, 2013). Interestingly, we did not find a similar moderating effect for brands perceived as being predominantly hedonic. One reason might be that most of the brands used in our study (with the exception of Armani and Heineken) were perceived as predominantly utilitarian brands. However, we find that brands' utilitarian features impact directly and positively the brand stereotype content in terms of warmth. This result indicates that the perceived functional features of a brand can boost its warmth 
independently of the brand's origin. Therefore, while previous studies have linked country warmth with hedonic product properties and country competence with utilitarian product properties (Chattalas, 2015; Chattalas and Takada, 2013), we reveal that, for the brands selected for our study, utilitarianism impacts positively both the brand warmth and brand competence dimensions.

Our research provides the first empirical attempt to assess the predictive validity of the $\mathrm{SCM}$ on consumer response variables using both country and brand stereotypes as drivers of managerially relevant consumer outcomes. Country stereotypes impact the outcome variables only indirectly, that is, through content transfer to the brand stereotypes; the latter thus fully mediate the link between country stereotypes and brand attitude, which then impacts purchase intentions. We thus demonstrate that brand stereotypes are an important explanatory link between country stereotypes and consumer outcomes. Our research thus not only confirms existing propositions highlighting the suitability of the SCM for use in a branding context (e.g. Kervyn et al., 2012; Kolbl et al., 2020) but also points toward including brand stereotypes as mediators between country stereotypes and consumer outcomes.

Regarding the relative diagnosticity of the SCM dimensions, whereas prior research has questioned the relevance of country warmth (e.g. Chen et al., 2014); our findings highlight the diagnosticity of both country and brand warmth. Consistent with previous studies (e.g. Kolbl et al., 2019; Xu et al., 2013), our research further confirms the importance of warmth. For the stereotype content transfer, country warmth appears to be an equally strong predictor of brand warmth as country competence of brand competence. Brand warmth is also diagnostic in predicting brand attitude; however, compared to brand competence, it plays a smaller role. Nevertheless, underplaying the role of warmth in purchase decision contexts does not seem to be justified.

\subsection{Managerial implications}

A key implication of our findings for practitioners is that both consumers' stereotypical perceptions of a brand's $\mathrm{COO}$ and their stereotypical perceptions of the brand itself are of relevance for understanding and predicting consumers' reactions to brands. The two stereotypes are distinct yet interconnected by content transfer from the country to the brand, which, in turn, positively impacts behavioral intentions through brand attitude. However, such stereotype content transfer is far from being complete, that is, only a modest amount of country warmth (competence) can be expected to "spill over" to brand warmth (competence). To illustrate, the perceived competence of Sweden will be reflected to a certain extent in the perceived competence of IKEA products (see Figure 2). This implies that a sole focus by managers on country stereotypes (e.g. accentuating or downplaying the brand origin as often recommended in the mainstream COO literature) may lead to a suboptimal strategy for stimulating positive consumer responses. Practitioners are advised to explicitly also focus on strengthening the specific brand's stereotype by accentuating its warmth (e.g. highlighting pleasant feelings it may evoke for the consumer) and competence (e.g. emphasizing innovative attributes of the brand). In doing so and in order to fully benefit from the positive spillover effects of the country stereotype on the brand stereotype, managers should be careful in establishing an authentic and consonant connection between country competence/ warmth and their specific brand (Magnusson et al., 2019). Since positive country warmth (competence) judgments partially transfer to positive brand warmth (competence) judgments, managers should take advantage of such transfer. As an example, IKEA is practicing this by using not only its origin's national colors (i.e. blue and yellow) in its brand logo but also linguistic cues (e.g. Swedish accent in a German-speaking advertisement) and national symbols (e.g. elk/moose) in its brand communications. This provides a consonant (i.e. Sweden is stereotyped in our sample as a high competence and high-warmth country and so 
is IKEA) and authentic (i.e. Swedish stereotypes linked to a Swedish brand) connection. On the other hand, Zara (stereotyped in our sample as having average competence and low warmth) could benefit more from its origin's (i.e. Spain) relatively high warmth by establishing a more consonant country-brand stereotype; for example, by stressing Spanish people's friendliness and "joie de vivre" in its brand communications.

On a more general level, focusing on the match between country warmth/competence and brand warmth/competence may be more promising, particularly when judgments of the country stereotype outperform the brand stereotype. If a brand's $\mathrm{COO}$ is perceived as warm, this categorization will partly reinforce perceptions toward the specific brand as being warm. Thus, by establishing congruence between country warmth and brand warmth (such as depicting "made in" labels or national symbols in brand communications), the brand can take advantage of its origin. However, if a brand (e.g. Apple) is seen as more competent than its origin (USA), emphasizing the competence of its origin could be counterproductive.

Managers also need to be aware that while a brand's typicality of its origin will not amplify the positive stereotype content transfer, it will independently boost perceptions of brand warmth and competence. Emphasizing typicality in brand communications can thus stimulate a more favorable brand stereotype, over and above consumers' stereotypical perceptions of the brand's COO. Our findings further imply that in strengthening the country competence-brand competence bond, the brand's functionality plays an important role. Those brands perceived as being relatively more utilitarian than hedonic can additionally benefit from a stronger country-brand bond in terms of competence.

Our findings also inform practitioners that brands capable of generating favorable stereotypical perceptions of warmth and competence are more likely to encourage brand purchase. Marketing managers are thus advised to actively communicate both the warmth (e.g. good intentions) and the competence (e.g. performance) of their brands as these dimensions work in conjunction in favorably impacting purchase decisions through brand attitude. Such perceptions may be encouraged through positioning strategies, advertising, product packages and/or promotions. For instance, well-known brands that have been successful in this effort are those conveying corporate responsibility values and engagement (e.g. Ben and Jerry's, TOMS Shoes and The Body Shop). Since for-profit companies are often seen as competent but not warm (Aaker et al., 2010), enhancing the warmth-related stereotype dimension is likely to significantly benefit such brands. At the same time, managers need to be aware that the perceived stereotypical competence of brands is a stronger driver of favorable attitudes toward brands than their perceived stereotypical warmth.

\subsection{Limitations and future research}

Future research should further disentangle the role of typicality in conjunction with country and brand stereotypes since "little is known about how product cues and brand cues interact with origin-typicality, ... [and] the field is ripe for more research, especially in the area of origin-atypical products" (Spielmann, 2016, p. 1136). Bearing in mind that several of the stimuli we used in this research were brands rather typical of their COO (e.g. Mercedes and Germany), studies with atypical brands (e.g. Red Bull and Austria) should provide a more fine-grained understanding of the role of typicality, either as an antecedent of the brand stereotype, or as a moderator variable on the stereotype content transfer.

Second, our study is based on global brands and consumer responses from a developed country. While the external validity of our results might indeed be overestimated if generalized to less known countries or brands, external validity might also be underestimated if applied to consumers from less developed countries who tend to rely even more on country stereotypes from developed countries when evaluating products/brands (e.g. see Batra et al., 2000). Although our research shows the potential of stereotype content transfer from country to 
brand, this transfer inevitably depends on some preexisting stereotypes associated with the COO. For example, if a specific country is less known to consumers, it might be difficult to rely on specific country stereotypes and thus stereotype content transfer may be more problematic.

Third, the role of brands' perceived hedonic nature in conjunction with consumer stereotyping needs more attention. While people can perceive brands as having different combinations of hedonic and utilitarian properties and the majority of investigated product categories/brands depict indeed high levels of both utilitarian and hedonic benefits (Voss et al., 2003), it would be of value shedding light on whether and how stereotype content interacts with brands seen as predominantly hedonic.

Fourth, the relationship between stereotypes and behavioral tendencies may be mediated by emotions (Cuddy et al., 2007), which were not investigated in the current study. For instance, Maher and Carter (2011) found that country affect (i.e. admiration and contempt) fully mediates the relationship between perceived country warmth and willingness to buy. In this context, the Behaviors from Intergroup Affect and Stereotypes (BIAS) map from social psychology (Cuddy et al., 2007), which builds upon the SCM, offers a useful tool to operationalize and simultaneously examine the cognitive and affective components of stereotypes.

Fifth, consumer behavior may be also influenced by a third type of a stereotype, not considered in the present study, namely the brand buyer/user stereotype (e.g. Antonetti and Maklan, 2016). Brand users are not only visible when they purchase or use a branded a product but are also often depicted in advertising and social media marketing. Given that the desire to emulate brand users is central in the diffusion or rejection of consumption patterns, future research should investigate brand user stereotypes and their interaction with country and brand stereotypes in predicting brand evaluations and behavioral intentions.

Sixth, future research could explore a different order of stereotype content transfer than the one analyzed in the current study. Consistent with the "summary construct" hypothesis in COO research, whereby "consumers make abstractions of product information into country image" (Han, 1989, p. 223) as well as with the emerging literature on "reverse" COO effects (e.g. Lee and Lockshin, 2012; Ryu et al., 2016), the possibility that stereotypical content associated with a set of brands with the same origin may transfer over to the stereotype content of that origin should be investigated. Such research needs to employ a within-subjects design with respondents being exposed to several brand stimuli (from different product categories) so as to enable the "chunking" of brand stereotypical judgments into higher order units, eventually shaping the country stereotype.

Finally, we captured country and brand stereotypes via self-report measures. However, consumers may sometimes be reluctant to admit their stereotypical beliefs or even be unaware of their own stereotypes (Herz and Diamantopoulos, 2013). Future research could therefore benefit from employing indirect/implicit measures (Diamantopoulos et al., 2017).

In conclusion, research focusing on multiple stereotypes and their interrelations is still at its infancy, offering several interesting opportunities for further study. We hope that the current paper will act as a springboard for future endeavors in this important but underresearched area.

\section{References}

Aaker, J.L. (1997), "Dimensions of brand personality”, Journal of Marketing Research, Vol. 34 No. 3, pp. 347-356.

Aaker, J., Vohs, K.D. and Mogilner, C. (2010), "Nonprofits are seen as warm and for-profits as competent: firm stereotypes matter", Journal of Consumer Research, Vol. 37 No. 2, pp. 224-237.

Aaker, J.L., Garbinsky, E.N. and Vohs, K.D. (2012), "Cultivating admiration in brands: warmth, competence, and landing in the 'golden quadrant", Journal of Consumer Psychology, Vol. 22 No. 2, pp. 191-194.
Bond between

country and brand stereotypes

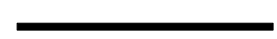


Andéhn, M. and L'Espoir Decosta, P. (2016), "The variable nature of country-to-brand association and its impact on the strength of the country-of-origin effect", International Marketing Review, Vol. 33 No. 6, pp. 851-866.

Antonetti, P. and Maklan, S. (2016), "Hippies, greenies, and tree huggers: how the 'warmth' stereotype hinders the adoption of responsible brands", Psychology and Marketing, Vol. 33 No. 10, pp. 796-813.

Batra, R. and Ahtola, O.T. (1991), "Measuring the hedonic and utilitarian sources of consumer attitudes”, Marketing Letters, Vol. 2 No. 2, pp. 159-170.

Batra, R., Ramaswamy, V., Alden, D.L., Steenkamp, J.B.E. and Ramachander, S. (2000), "Effects of brand local and nonlocal origin on consumer attitudes in developing countries", Journal of Consumer Psychology, Vol. 9 No. 2, pp. 83-95.

Bodenhausen, G.V. (1993), "Emotions, arousal, and stereotypic judgments: a heuristic model of affect and stereotyping", in Mackie, D.M. and Hamilton, D.L. (Eds), Affect, Cognition and Stereotyping, Academic Press, pp. 13-37.

Brijs, K., Bloemer, J. and Kasper, H. (2011), "Country-image discourse model: unraveling meaning, structure, and function of country images", Journal of Business Research, Vol. 64 No. 12, pp. 1259-1269.

Campbell, M.C. and Keller, K.L. (2003), "Brand familiarity and advertising repetition effects", Journal of Consumer Research, Vol. 30 No. 2, pp. 292-304.

Chattalas, M. (2015), "National stereotype effects on consumer expectations and purchase likelihood: competent versus warm countries of origin", Journal of Business and Retail Management Research, Vol. 10 No. 1, pp. 1-15.

Chattalas, M. and Takada, H. (2013), "Warm versus competent countries: national stereotyping effects on expectations of hedonic versus utilitarian product properties", Place Branding and Public Diplomacy, Vol. 9 No. 2, pp. 88-97.

Chattalas, M., Kramer, T. and Takada, H. (2008), "The impact of national stereotypes on the country of origin effect: a conceptual framework", International Marketing Review, Vol. 25 No. 1, pp. 54-74.

Chen, C.Y., Mathur, P. and Maheswaran, D. (2014), "The effects of country-related affect on product evaluations", Journal of Consumer Research, Vol. 41 No. 4, pp. 1033-1046.

Cho, E. and Fiore, A.M. (2015), "Conceptualization of a holistic brand image measure for fashionrelated brands", Journal of Consumer Marketing, Vol. 32 No. 4, pp. 255-265.

Cohen, J. (1988), Statistical Power Analysis for the Behavioral Sciences, Lawrence Erlbaum Associates, Hillsdale, NJ.

Cuddy, A.J., Fiske, S.T. and Glick, P. (2007), "The BIAS map: behaviors from intergroup affect and stereotypes", Journal of Personality and Social Psychology, Vol. 92 No. 4, pp. 631-648.

Davvetas, V. and Halkias, G. (2019), "Global and local brand stereotypes: formation, content transfer, and impact”, International Marketing Review, Vol. 36 No. 5, pp. 675-701.

Dholakia, R.R., Zhao, M. and Duan, J. (2020), "The COO construct: methodological and related issues in a globalized world”, Journal of Global Marketing, Vol. 33 No. 1, pp. 3-17.

Diamantopoulos, A., Smith, G. and Grime, I. (2005), "The impact of brand extensions on brand personality: experimental evidence", European Journal of Marketing, Vol. 39 Nos 1/2, pp. 129-149.

Diamantopoulos, A., Schlegelmilch, B. and Palihawadana, D. (2011), "The relationship between country-of-origin image and brand image as drivers of purchase intentions: a test of alternative perspectives”, International Marketing Review, Vol. 28 No. 5, pp. 508-524.

Diamantopoulos, A., Florack, A., Halkias, G. and Palcu, J. (2017), "Explicit versus implicit country stereotypes as predictors of product preferences: insights from the stereotype content model”, Journal of International Business Studies, Vol. 48 No. 8, pp. 1023-1036. 
Dobni, D. and Zinkhan, G.M. (1990), "In search of brand image: a foundation analysis", in Goldberg, M.E., Gorn, G. and Pollay, R.W. (Eds), NA - Advances in Consumer Research, Association for Consumer Research, Provo, UT, Vol. 17, pp. 110-119.

Dodds, W.B., Monroe, K.B. and Grewal, D. (1991), "Effects of price, brand, and store information on buyers' product evaluations", Journal of Marketing Research, Vol. 28 No. 3, pp. 307-319.

Fiske, S.T. (2018), "Stereotype content: warmth and competence endure", Current Directions in Psychological Science, Vol. 27 No. 2, pp. 67-73.

Fiske, S.T., Cuddy, A.J., Glick, P. and Xu, J. (2002), "A model of (often mixed) stereotype content: competence and warmth respectively follow from perceived status and competition", Journal of Personality and Social Psychology, Vol. 82 No. 6, pp. 878-902.

Fornell, C. and Larcker, D.F. (1981), "Evaluating structural equation models with unobservable variables and measurement error", Journal of Marketing Research, Vol. 18 No. 1, pp. 39-50.

Fournier, S. (1998), "Consumers and their brands: developing relationship theory in consumer research", Journal of Consumer Research, Vol. 24 No. 4, pp. 343-373.

Fournier, S. (2009), "Lessons learned about consumers' relationships with their brands", in Priester, J., MacInnis, D. and Park, C.W. (Eds), Handbook of Brand Relationships, Society for Consumer Psychology and M. E. Sharp, N.Y, pp. 5-23.

Fournier, S. and Alvarez, C. (2012), "Brands as relationship partners: warmth, competence, and inbetween”, Journal of Consumer Psychology, Vol. 22 No. 2, pp. 177-185.

Gong, S., Sheng, G., Peverelli, P. and Dai, J. (2020), "Green branding effects on consumer response: examining a brand stereotype-based mechanism", Journal of Product and Brand Management. doi: 10.1108/JPBM-03-2020-2785 (in press).

Greenwald, A.G. and Banaji, M.R. (1995), "Implicit social cognition: attitudes, self-esteem, and stereotypes", Psychological Review, Vol. 102 No. 1, pp. 4-27.

Guthrie, S.E. (1995), Faces in the Clouds: A New Theory of Religion, Oxford University Press, Oxford.

Halkias, G. and Diamantopoulos, A. (2020), "Universal dimensions of individuals' perception: revisiting the operationalization of warmth and competence with a mixed-method approach", International Journal of Research in Marketing, Vol. 37 No. 4, pp. 714-736.

Halkias, G., Davvetas, V. and Diamantopoulos, A. (2016), "The interplay between country stereotypes and perceived brand globalness/localness as drivers of brand preference", Journal of Business Research, Vol. 69 No. 9, pp. 3621-3628.

Hamzaoui-Essoussi, L., Merunka, D. and Bartikowski, B. (2011), "Brand origin and country of manufacture influences on brand equity and the moderating role of brand typicality", Journal of Business Research, Vol. 64 No. 9, pp. 973-978.

Han, C.M. (1989), "Country image: halo or summary construct?", Journal of Marketing Research, Vol. 26 No. 2, pp. 222-229.

Hayes, A.F. (2018), Introduction to Mediation, Moderation, and Conditional Process Analysis: A Regression-Based Approach, Guilford Press, New York, NY.

Herz, M.F. and Diamantopoulos, A. (2013), "Activation of country stereotypes: automaticity, consonance, and impact", Journal of the Academy of Marketing Science, Vol. 41 No. 4, pp. 400-417.

Ivens, B.S., Leischnig, A., Muller, B. and Valta, K. (2015), "On the role of brand stereotypes in shaping consumer response toward brands: an empirical examination of direct and mediating effects of warmth and competence", Psychology and Marketing, Vol. 32 No. 8, pp. 808-820.

Jaffe, E.D. and Nebenzahl, I.D. (2006), National Images and Competitive Advantage: the Theory and Practice of Place Branding, Copenhagen Business School Press, Copenhagen.

Josiassen, A., Lukas, B.A., Whitwell, G.J. and Assaf, A.G. (2013), "The halo model of origin images: conceptualisation and initial empirical test", Journal of Consumer Behaviour, Vol. 12 No. 4, pp. 253-266. 
Keller, K.L. and Aaker, D.A. (1992), "The effects of sequential introduction of brand extensions", Journal of Marketing Research, Vol. 29 No. 1, pp. 35-50.

Kervyn, N., Yzerbyt, V.Y., Demoulin, S. and Judd, C.M. (2008), "Competence and warmth in context: the compensatory nature of stereotypic views of national groups", European Journal of Social Psychology, Vol. 38 No. 7, pp. 1175-1183.

Kervyn, N., Fiske, S.T. and Malone, C. (2012), "Brands as intentional agents framework: how perceived intentions and ability can map brand perception”, Journal of Consumer Psychology, Vol. 22 No. 2, pp. 166-176.

Kolbl, Ž., Arslanagic-Kalajdzic, M. and Diamantopoulos, A. (2019), "Stereotyping global brands: is warmth more important than competence?", Journal of Business Research, Vol. 104 November, pp. 614-621.

Kolbl, Ž., Diamantopoulos, A., Arslanagic-Kalajdzic, M. and Žabkar, V. (2020), "Do brand warmth and brand competence add value to consumers? A stereotyping perspective", Journal of Business Research, Vol. 118, pp. 346-362.

Lee, T.L. and Fiske, S.T. (2006), "Not an outgroup, not yet an ingroup: immigrants in the stereotype content model", International Journal of Intercultural Relations, Vol. 30 No. 6, pp. 751-768.

Lee, R. and Lockshin, L. (2012), "Reverse country-of-origin effects of product perceptions on destination image", Journal of Travel Research, Vol. 51 No. 4, pp. 502-511.

Lindell, M.K. and Whitney, D.J. (2001), "Accounting for common method variance in cross-sectional research designs", Journal of Applied Psychology, Vol. 86 No. 1, pp. 114-121.

Loken, B. and Ward, J. (1990), "Alternative approaches to understanding the determinants of typicality”, Journal of Consumer Research, Vol. 17 No. 2, pp. 111-126.

Macrae, C.N., Milne, A.B. and Bodenhausen, G.V. (1994), "Stereotypes as energy-saving devices: a peek inside the cognitive toolbox", Journal of Personality and Social Psychology, Vol. 66 No. 1, pp. 37-44.

Magnusson, P., Westjohn, S.A. and Sirianni, N.J. (2019), "Beyond country image favorability: how brand positioning via country personality stereotypes enhances brand evaluations", Journal of International Business Studies, Vol. 50 No. 3, pp. 318-338.

Maher, A.A. and Carter, L.L. (2011), "The affective and cognitive components of country image: perceptions of American products in Kuwait”, International Marketing Review, Vol. 28 No. 6, pp. 559-580.

Maheswaran, D. (1994), "Country of origin as a stereotype: effects of consumer expertise and attribute strength on product evaluations", Journal of Consumer Research, Vol. 21 No. 2, pp. 354-365.

Miyazaki, A.D., Grewal, D. and Goodstein, R.C. (2005), "The effect of multiple extrinsic cues on quality perceptions: a matter of consistency", Journal of Consumer Research, Vol. 32 No. 1, pp. 146-153.

Motsi, T. and Park, J.E. (2019), "National stereotypes as antecedents of country-of-origin image: the role of the stereotype content model", Journal of International Consumer Marketing, Vol. 32 No. 2, pp. 115-127.

Nebenzahl, I.D., Jaffe, E.D. and Usunier, J.C. (2003), "Personifying country of origin research", Management International Review, Vol. 43 No. 4, pp. 383-406.

Oakes, P.J. and Turner, J.C. (1990), "Is limited information processing capacity the cause of social stereotyping?", European Review of Social Psychology, Vol. 1 No. 1, pp. 111-135.

Oakes, P.J., Turner, J.C. and Haslam, S.A. (1991), "Perceiving people as group members: the role of fit in the salience of social categorizations", British Journal of Social Psychology, Vol. 30 No. 2, pp. 125-144.

Oberecker, E.M., Riefler, P. and Diamantopoulos, A. (2008), "The consumer affinity construct: conceptualization, qualitative investigation, and research agenda", Journal of International Marketing, Vol. 16 No. 3, pp. 23-56. 
Pappu, R., Quester, P.G. and Cooksey, R.W. (2007), "Country image and consumer-based brand equity: relationships and implications for international marketing", Journal of International Business Studies, Vol. 38 No. 5, pp. 726-745.

Podsakoff, P.M., MacKenzie, S.B., Lee, J.Y. and Podsakoff, N.P. (2003), "Common method biases in behavioral research: a critical review of the literature and recommended remedies", Journal of Applied Psychology, Vol. 88 No. 5, pp. 879-903.

Roth, K.P. and Diamantopoulos, A. (2009), "Advancing the country image construct", Journal of Business Research, Vol. 62 No. 7, pp. 726-740.

Ryu, J.S., Decosta, J.P.L.E. and Andéhn, M. (2016), "From branded exports to traveler imports: building destination image on the factory floor in South Korea", Tourism Management, Vol. 52, pp. 298-309.

Samiee, S. (1994), "Customer evaluation of products in a global market", Journal of International Business Studies, Vol. 25 No. 3, pp. 579-604.

Spielmann, N. (2016), "Is it all or nothing? Testing schema congruity and typicality for products with country origin", Journal of Business Research, Vol. 69 No. 3, pp. 1130-1137.

Teas, R.K. and Agarwal, S. (2000), "The effects of extrinsic product cues on consumers' perceptions of quality, sacrifice, and value", Journal of the Academy of Marketing Science, Vol. 28 No. 2, pp. 278-290.

Teichert, T.A. and Schöntag, K. (2010), "Exploring consumer knowledge structures using associative network analysis", Psychology and Marketing, Vol. 27 No. 4, pp. 369-398.

Tseng, T.H. and Balabanis, G. (2011), "Explaining the product-specificity of country-of-origin effects", International Marketing Review, Vol. 28 No. 6, pp. 581-600.

Usunier, J.C. and Cestre, G. (2007), "Product ethnicity: revisiting the match between products and countries", Journal of International Marketing, Vol. 15 No. 3, pp. 32-72.

Verlegh, P.W. (2001), Country-of-origin Effects on Consumer Product Evaluations, Unpublished $\mathrm{PhD}$ Dissertation, Wageningen University, The Netherlands.

Voss, K.E., Spangenberg, E.R. and Grohmann, B. (2003), "Measuring the hedonic and utilitarian dimensions of consumer attitude", Journal of Marketing Research, Vol. 40 No. 3, pp. 310-320.

Wu, J., Chen, J. and Dou, W. (2017), “The Internet of Things and interaction style: the effect of smart interaction on brand attachment", Journal of Marketing Management, Vol. 33 Nos 1-2, pp. 61-75.

$\mathrm{Xu}, \mathrm{H}$., Leung, A. and Yan, R.N. (2013), "It is nice to be important, but it is more important to be nice: country-of-origin's perceived warmth in product failures", Journal of Consumer Behaviour, Vol. 12 No. 4, pp. 285-292.

\section{Corresponding author}

Ilona Szöcs can be contacted at: ilona.szoecs@univie.ac.at

For instructions on how to order reprints of this article, please visit our website:

www.emeraldgrouppublishing.com/licensing/reprints.htm

Or contact us for further details: permissions@emeraldinsight.com 